\section{Trends of and factors associated with cesarean section related surgical site infections in Guinea}

\author{
Alexandre Delamou, ${ }^{1-3}$ \\ Bienvenu Salim Camara, ${ }^{3}$ \\ Sidikiba Sidibé, ${ }^{1-3}$ Alioune Camara, ${ }^{1}$ \\ Nafissatou Dioubaté, ${ }^{3}$ \\ Alison Marie El Ayadi, ${ }^{4}$ \\ Katy Tayler-Smith, 5 \\ Abdoul Habib Beavogui, ${ }^{3}$ \\ Mamadou Dioulde Baldé, ${ }^{6}$ \\ Rony Zachariah ${ }^{5}$ \\ 1'Department of Public Health, Gamal \\ University of Conakry, Conakry, \\ Guinea; ${ }^{2}$ Woman and Child Health \\ Research Centre, Institute of Tropical \\ Medicine, Antwerp, Belgium; \\ ${ }^{3}$ Centre National de Formation et de \\ Recherche en Santé Rurale de \\ Maferinyah, Maferinyah, Guinea; \\ ${ }^{4}$ University of California, Bixby Center \\ for Global Reproductive Health, San \\ Francisco, CA, USA; ${ }^{5}$ Médecins sans \\ Frontières, Medical Department, \\ Operational Centre Brussels, MSF- \\ Luxembourg, Luxembourg; \\ ${ }^{6}$ Department of Gynecology and \\ Obstetrics, Gamal University of \\ Conakry, Conakry, Guinea
}

\begin{abstract}
Since the adoption of free obstetric care policy in Guinea in 2011, no study has examined the surgical site infections in maternity facilities. The objective of this study was to assess the trends of and factors associated with surgical site infection following cesarean section in Guinean maternity facilities from 2013 to 2015. This was a retrospective cohort study using routine medical data from ten facilities. Overall, the incidence of surgical site infections following cesarean section showed a declining trend across the three periods (10\% in 2013, 7\% in 2014 and 5\% in 2015, $\mathrm{P}<0.001)$. Women who underwent cesarean section in 2014 (AOR: 0.70; 95\%CI: 0.57-0.84) and 2015 (AOR: 0.43; 95\%CI: $0.34-0.55)$ were less likely to develop surgical site infections during hospital stay than women operated in 2013. In the contrary, women with comorbidities were more likely to experience surgical site infection (AOR: $1.54 ; 95 \%$ CI: 1.25-1.90) than those who did not have comorbidities. The reductions achieved in 2014 and 2015 (during the Ebola outbreak) should be sustained in the post-Ebola context.
\end{abstract}

\section{Introduction}

A surgical site infection (SSI) is an infection that occurs post-surgery around the tissues of the body where the surgery occurred; it can be superficial, involving only the skin at incision site, or deeper involving the tissues under the skin, the organs, or implanted surgical material. ${ }^{1}$

Various factors influence the incidence of SSIs including the quality and level of implementation of infection prevention and control measures. ${ }^{2}$ The latter is often suboptimal in resource-constrained settings, contributing to a higher risk of SSIs. This includes among women undergoing obstetric interventions. ${ }^{2}$

One of the most common obstetric surgical interventions is a cesarean section (CS). A multi-country study conducted in sub-Saharan Africa from 2010 to 2011 reported a CS related SSI risk of $7.3 \% .^{3}$ Other studies have reported CS related SSI risks of $9.1 \%$ in Nigeria in 2001 and 2002, $7.2 \%$ in Cameroon in 2012, and $5.9 \%$ in Benin in 2009 and 2010.4-6 SSIs following CS may result in a higher risk of maternal morbidity or mortality, and additional financial and hospital resources related to longer hospital stays and higher treatment costs. ${ }^{7}$

In Guinea, the free obstetric care policy was adopted in $2011^{8}$ and might have increased utilization of obstetric care including cesarean section. This could result in increased workload (and reduced quality of care) leading in some contexts to more neonatal deaths and maternal complications. $^{8}$

In addition, the 2014/2015 Ebola Virus Disease (EVD) outbreak in West Africa was declared on 21 March 2014 in Guinea. ${ }^{9}$ The lack of adequate infection prevention and control measures in health facilities have been reported during the outbreak. ${ }^{10-12}$ To protect both HCWs and patients from facility-based infections, measures were rapidly undertaken to improve infection prevention and control measures in facilities, especially high-risk facilities such as maternities. This included the provision of relevant training for HCWs and the sufficient supply of necessary equipment to health facilities. ${ }^{13,14}$ while the main purpose of implementing these measures was to prevent the transmission of EVD, they may have had the unintended consequence of reducing SSIs, including those related to $\mathrm{CS}$. The incidence of SSIs is an indirect indicator of in-hospital quality of services and might give indication of how effective were the infection prevention measures implemented during the EVD outbreak in maternity hospitals. However, to date, we are unaware of any previous studies examining the SSIs in
Correspondence: Alexandre Delamou, Department of Public Health, Gamal University of Conakry, PO Box 4099 Conakry, Guinea.

Tel. :+224631099750.

E-mail: adelamou@gmail.com

Key words: Surgical site Infection; Cesarean section; Ebola virus disease; Guinea.

Acknowledgement: Chair of Public Health of the Gamal Abdel Nasser University of Conakry; Hospitals of the study districts; Structured Operational Research and Training Initiative (SORT IT)

Contributions: AD, BSC, SS and RZ were involved with conception and design of the protocol which was reviewed by $\mathrm{AC}, \mathrm{ND}$, AME, KT, AHB and MDB. AD, BSC, SS, AC and ND were involved with acquisition of data, and AD and BSC did the data analysis and all authors were involved with interpretation. The first draft manuscript was written by $\mathrm{AD}, \mathrm{BSC}$ and SS and critically reviewed by RZ and KTS, then by all co-authors. All authors have given approval for the final version to be published and are accountable. AD is the study guarantor of the present study.

Conflict of interest: the authors declare no potential conflict of interest.

Funding: none.

Received for publication: 15 November 2017. Accepted for publication: 19 July 2018.

This work is licensed under a Creative Commons Attribution NonCommercial 4.0 License (CC BY-NC 4.0).

CCopyright A. Delamou et al., 2019

Licensee PAGEPress, Italy

Journal of Public Health in Africa 2019; 10:818 doi:10.4081/jphia.2019.818

Guinea. Therefore, the objective of this study was to assess the trends of and factors associated with surgical site infection following cesarean section in Guinean maternity facilities from 2013 to 2015 .

\section{Materials and Methods}

\section{Study design}

This was a retrospective cohort study using routine medical records from $1^{\text {st }}$ January 2013 to $31^{\text {st }}$ December 2015.

\section{Setting \\ General setting}

Guinea is a West African country comprising eight administrative regions and 34 districts. The country has a population of 
nearly 11 million inhabitants, predominantly rural dwelling $(65 \%)$ and living under the poverty line $(55 \%)$. Facility-based deliveries represented $40 \%$ of total deliveries in 2012 , of which only $2 \%$ were by CS..$^{15,16}$ In 2011, the Guinean Government established a free neonatal and obstetric care policy in all public health facilities, including CS. This policy was aimed at reducing maternal and neonatal mortality.

\section{Study setting}

At the time of the study, there were 33 rural maternity facilities in Guinea. The study sites included ten rural maternity facilities randomly selected. They included facilities from the districts of Boké, Coyah, Dubréka, Forécariah, Guéckédou, Kankan, Kindia, Labé, Nzérékoré and Télimélé. As of April $16^{\text {th }} 2016$, the study districts reported a total of 1,487 EVD confirmed cases ( $44 \%$ of all the cases nationwide), whereas they only represent $33 \%$ of the national population. ${ }^{9,15}$

\section{Study population and period}

The study included all women who underwent a cesarean section in the ten selected maternity facilities in Guinea between $1^{\text {st }}$ January 2013 and $31^{\text {st }}$ December 2015.

\section{Data collections, variables and sources of data}

Data were collected between September and November 2016, sourced from consultation registers, patient medical records and operative reports held at the study maternity facilities. The study variables included patients' socio-demographic characteristics (age, profession, level of education, residence (rural/urban), marital status, number of pregnancies), clinical characteristics (date of admission, admission diagnosis, co-morbidities, date of surgery, type of surgery performed, presence of an SSI (yes/no), if SSI present: infection site (cutaneous or cavity/viscera), date of infection occurrence, date of discharge/transfer/ death), and maternal outcome (discharge, transfer or death). For the purpose of the study, an SSI was defined as any wound infection associated with a CS occurring during a patient's admission up until their discharge/transfer/death. Data variables were collected using semi-structured forms and entered into an EpiData database (version 2.0.7.22 for entry EpiData Association, Odense, Denmark).

\section{Data analysis and statistics}

Descriptive data were summarized as proportions or median (25-75\% IQR). Monthly SSI incidence was calculated using the number of CSs per month and the number of CS-related SSIs. It was described over the periods of 2013, 2014 and 2015. The annual incidences of SSIs were compared, across the three time periods using the Pearson's Chi square test. To identify the factors associated with SSIs, the Pearson Chi Square, Fischer and Student's tests were used to compare the incidence of SSIs across study variables in bivariate analysis. All variables were included a priori in logistic regression models. The unadjusted and adjusted odds ratios were derived. Differences were considered statistically significant at $\mathrm{P} \leq 0.05$.

Data were analysed using STATA 13 software (Stata Corp, Texas, USA).

\section{Ethics approval}

Ethics approval was obtained from the Guinean National Ethics Committee for Health Research and satisfied the ethics criteria of the Médecins Sans Frontière Ethics Review Board (Geneva, Switzerland) for studies using routinely collected program data.

\section{Results}

\section{Characteristics of the study population}

A total of 7394 women who underwent a CS were included in the study. They were predominantly housewives $(64 \%)$ with no education level $(82 \%)$ and living in urban area $(66 \%)$ (Table 1$)$. Their median age was 25 years (25-75\% IQR: 20 to 30 years).

Table 1. Sociodemographic, clinical characteristics and outcomes of women undergoing cesarean sections in a selection of maternities in Guinea, 2013-2015 (N=7394).

\begin{tabular}{|c|c|c|}
\hline Characteristics & N. & $\%$ \\
\hline Median age (IQR), years ( $\mathrm{n}=7373)$ & $25(20 ; 30)$ & NA \\
\hline $\begin{array}{l}\text { Profession }(\mathrm{n}=7382) \\
\text { Housewife } \\
\text { Student } \\
\text { Workwoman } \\
\text { Seller } \\
\text { Other }\end{array}$ & $\begin{array}{l}4736 \\
857 \\
760 \\
707 \\
322\end{array}$ & $\begin{array}{c}64 \\
12 \\
10 \\
10 \\
4\end{array}$ \\
\hline $\begin{array}{l}\text { Level of education }(\mathrm{n}=7383) \\
\text { None } \\
\text { Primary or more }\end{array}$ & $\begin{array}{l}6045 \\
1338\end{array}$ & $\begin{array}{l}82 \\
18\end{array}$ \\
\hline $\begin{array}{l}\text { Residence }(\mathrm{n}=7370) \\
\text { Urban } \\
\text { Rural }\end{array}$ & $\begin{array}{l}4891 \\
2479\end{array}$ & $\begin{array}{l}66 \\
34\end{array}$ \\
\hline $\begin{array}{l}\text { Marital status }(\mathrm{n}=7388) \\
\text { Married/In union } \\
\text { Unmarried }\end{array}$ & $\begin{array}{c}6445 \\
943\end{array}$ & $\begin{array}{l}87 \\
13\end{array}$ \\
\hline Median no. of pregnancies (IQR) ( $\mathrm{n}=7168)$ & $2(1 ; 4)$ & NA \\
\hline $\begin{array}{l}\text { Admission diagnosis } \\
\text { Feto-pelvic disproportion } \\
\text { Hemorrhagic emergencies } \\
\text { Dystocia } \\
\text { Acute fetal distress } \\
\text { Prophylactic cesarean section } \\
\text { Other diagnoses } \\
\text { b }\end{array}$ & $\begin{array}{l}2288 \\
1493 \\
1330 \\
928 \\
697 \\
658\end{array}$ & $\begin{array}{l}31 \\
20 \\
18 \\
13 \\
9 \\
9\end{array}$ \\
\hline $\begin{array}{l}\text { Comorbidities } \\
\text { None } \\
\text { Malaria } \\
\text { Acute fetal distress } \\
\text { Anemia } \\
\text { Dystocia } \\
\text { Other comorbidities }{ }^{\mathrm{c}}\end{array}$ & $\begin{array}{c}6171 \\
369 \\
294 \\
249 \\
228 \\
83\end{array}$ & $\begin{array}{c}84 \\
5 \\
4 \\
3 \\
3 \\
1\end{array}$ \\
\hline Median duration of hospital stay (IQR), days & $4(3 ; 5)$ & NA \\
\hline $\begin{array}{l}\text { Maternal outcome } \\
\text { Discharge } \\
\text { Transfer } \\
\text { Death }\end{array}$ & $\begin{array}{c}7330 \\
19 \\
45\end{array}$ & $\begin{array}{l}99 \\
<1 \\
1\end{array}$ \\
\hline
\end{tabular}

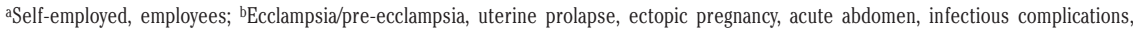
hydroamnios/oligoamnios, Hypertension, obstetric fistula. 'Hemorrhagic emergencies, heart diseases, diabetes, sickle cell disease, eclampsia/pre-eclampsia, obstetric fistula, physical disability, rheumatism, feto-pelvic disproportion, sexually transmitted diseases. Notes: missingness across all variables $\leq 1 \%$. 
Most of them were married/in union (87\%) with a median number of 2 pregnancies (2575\% IQR: 1 to 4 pregnancies). Women's admission diagnoses mainly included fetopelvic disproportion (31\%), hemorrhagic emergencies $(20 \%)$, dystocia $(18 \%)$, acute fetal distress $(13 \%)$ and prophylactic cesarean section $(9 \%)$. The proportions of women presenting with comorbidities was $16 \%, 5 \%$ for malaria, $4 \%$ for acute fetal distress, $3 \%$ for anemia and $3 \%$ for dystocia. Maternal mortality represented $1 \%$.

\section{Incidence of surgical site infections from 2013 to 2015}

Overall, SSI incidence following CS decreased across the three periods, from $10 \%$ in 2013 , to $7 \%$ in 2014 and $5 \%$ in 2015 $(\mathrm{P}<0.001$; Figure 1). In most cases, the SSI was cutaneous in nature across the three periods (88\% in 2013, 93\% in 2014 and $89 \%$ in 2015). The monthly trends showed considerable declines in CS-related SSIs in 2014, falling from a peak of $13 \%$ in December 2013 to a low of $1 \%$ in November 2014. In 2015, the proportion of women developing an SSI increased slightly from $4 \%$ to $6 \%$ overall.

\section{Factors associated with surgical site infections}

In bivariate analysis, we found that the year of surgery, the number of pregnancies, and the comorbidities were statistically sig- nificantly associated with surgical site infection following cesarean section (Table 2). However, after adjusting for possible confounding variables, only the year of surgery and the comorbidities remained independently associated with surgical site infection following cesarean section. Women who underwent cesarean section in 2014 (AOR: 0.70; 95\% CI: 0.57-0.84) and in 2015 (AOR: 0.43; 95\% CI: 0.34-0.55) were less likely to experience an SSI than women who had surgery in 2013. In the contrary, women with comorbidities were more likely to experience an SSI (AOR: 1.54; 95\% CI: $1.25-1.90)$ compared to those who did not have comorbidities.

\section{Discussion}

This is the first study to examine the trends of and factors associated with cesarean section related surgical site infections since the adoption of the free obstetric care policy in Guinea. Overall the SSI incidence was lower in 2014 and 2015 compared to 2013. SSIs were statistically significantly associated with the year of the caesarean section and the presence of comorbidities. SSIs are subject to substantial mortality and morbidity and impose heavy demands on healthcare resources, ${ }^{3}$ thus our findings raise some important points for discussion.
First, in 2013 (prior to the EVD outbreak in Guinea), the risk of a CS-related SSI in the maternity facilities studied was similar to that reported from other poor resource settings. ${ }^{3-6}$ But in 2014 and 2015 (during the EVD outbreak), a significant fall in SSI incidence was observed. Women who underwent caesarean section in 2014 and 2015 had respectively $30 \%$ and $57 \%$ less risk of developing SSI compared to those who underwent caesarean section in 2013. The reinforcement of infection prevention measures as result of the response to the $\mathrm{EVD}^{14,17}$ might have led to the reduction in SSIs incidence. During the EVD outbreak in Guinea, infection prevention and control measures included training of HCWs in all facilities, especially in maternity units, and provision of sufficient supplies of personal protective equipment, chlorine solution and waste bins. For instance, all surgical and obstetric devices were sterilized and the whole delivery suite properly cleaned with chlorine solution before any intervention; patients and their relatives were required to wash their hands with chlorine at the entrance gate before accessing the wards. However, our study does not allow us to causally attribute this association. The decreased trend of SSIs could also be attributed to disruption of maternal health services, whereby many women or health care workers deserted hospital and clinical activities were not well

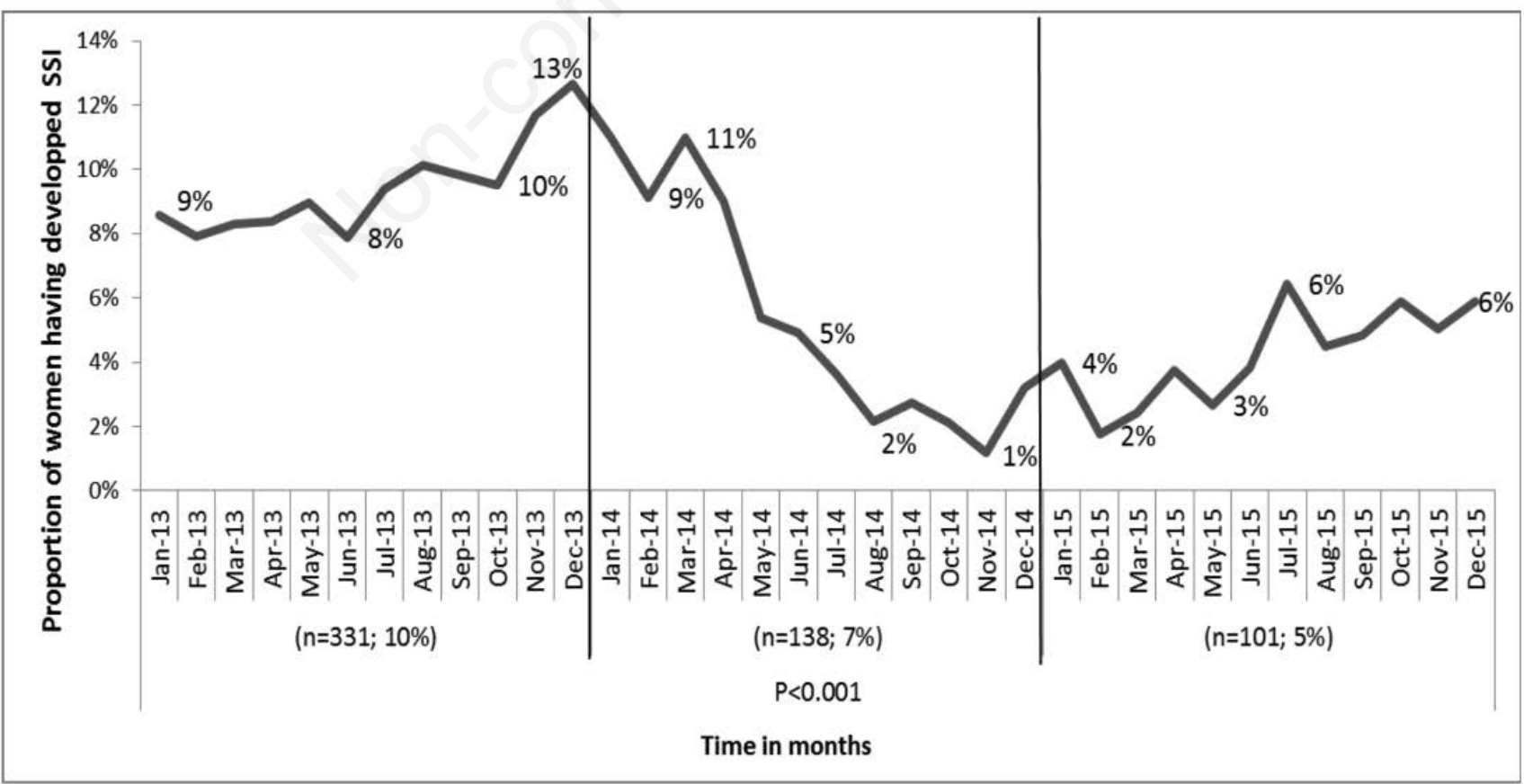

Figure 1. Trends in Surgical Site Infection (SSI) incidence among women undergoing caesarian section in a selection of maternities in Guinea, 2013-2015 (N=7394). 
documented. ${ }^{18-21}$ Although our study does not allow us to causally attribute this association, our results are consistent with other studies that have shown a direct link between comprehensive infection control measures and lower SSI incidence. ${ }^{22-25}$

Further research on the link between EVD related infection prevention and control measures and the observed decrease in the incidence of SSIs could guide post-EVD policy and practices toward the reduction of in-hospital maternal mortality and morbidity in Guinea. Second, the monthly trend of SSIs reached its lowest in 2014 then progressively and slightly rose back during 2015. Unobserved changes in documentation during the EVD period (especially over the first months of the outbreak) could impact the reporting of SSIs, probably resulting in the picture of the trend seen in 2014. The impact of EVD outbreak on the health systems of the affected countries ${ }^{19,26}$ might have negatively interfered with the health data reporting systems. The increase in SSIs noted in 2015, a year after the onset of the outbreak, may relate to a gradual recovery of the health system resulting in surveillance data better reflecting the reality (i.e., returning to baseline). In addition to the need for further investigation on the causality of the SSIs reduction during the EVD outbreak, this study suggests appropriate measures for a sustained and resilient health data reporting system regardless the occurrence of any outbreak.

This study has a limitation. SSIs are typically defined as occurring at any time during the thirty day post-surgery period, regardess of discharge status. Thus, a certain proportion of women may have developed an SSI after discharge which was not captured. This may have underestimated
SSI incidence. However, the same definition was applied to the three study periods, which allows comparisons.

\section{Conclusions}

Our study shows that CS-related SSIs significantly dropped in 2014 and 2015 (during the EVD outbreak) as compared to 2013 and were associated with the year of the cesarean section and the presence of comorbidities.

The comprehensive infection prevention and control measures introduced during the Ebola outbreak in maternal and child health services in Guinea were the likely reasons for change over time of SSI. The reductions achieved should be sustained in the post-Ebola context.

Table 2. Factors associated with surgical site infection among of women undergoing cesarean section in a selection of maternities in Guinea, 2013-2015.

\begin{tabular}{|c|c|c|c|c|}
\hline \multirow[t]{2}{*}{ Characteristics } & \multicolumn{4}{|c|}{ Surgical site infection (yes) } \\
\hline & $\mathbf{N}(\%)$ & Unadjusted OR (95\% CI) & Adjusted OR (95\% CI) & P-value \\
\hline $\begin{array}{l}\text { Year } \\
2013 \\
2014 \\
2015\end{array}$ & $\begin{array}{l}331(10) \\
138(7) \\
101(5)\end{array}$ & $\begin{array}{c}1 \\
0.69(0.56-0.84) \\
0.43(0.34-0.53)\end{array}$ & $\begin{array}{c}1 \\
0.70(0.57-0.82) \\
0.43(0.34-0.55)\end{array}$ & $\begin{array}{l}0.001 \\
<0.001\end{array}$ \\
\hline Mean age (SD), years & $25(7)$ & $1.00(0.99-1.02)$ & - & 0.460 \\
\hline $\begin{array}{l}\text { Profession } \\
\text { Housewife } \\
\text { Other professiona }\end{array}$ & $\begin{array}{l}378(8) \\
192(7)\end{array}$ & $0.92(0.75-1.08)$ & - & 0.263 \\
\hline $\begin{array}{l}\text { Level of education } \\
\text { None } \\
\text { Primary or more } \\
\end{array}$ & $\begin{array}{l}469(8) \\
100(7)\end{array}$ & $0.96(0.77-1.20)$ & - & 0.724 \\
\hline $\begin{array}{l}\text { Residence } \\
\text { Urban } \\
\text { Rural }\end{array}$ & $\begin{array}{l}372(8) \\
197(8)\end{array}$ & $\begin{array}{c}1 \\
1.05(0.88-1.26)\end{array}$ & - & 0.604 \\
\hline $\begin{array}{l}\text { Marital status } \\
\text { Married/In union } \\
\text { Unmarried }\end{array}$ & $\begin{array}{l}505(8) \\
65(7)\end{array}$ & $\begin{array}{c}1 \\
0.87(0.67-1.14)\end{array}$ & - & 0.311 \\
\hline Mean no. of pregnancies (SD) & $3(2)$ & $1.05(1.01-1.09)$ & $1.04(0.99-1.08)$ & 0.085 \\
\hline $\begin{array}{l}\text { Admission diagnosis } \\
\text { Feto-pelvic disproportion } \\
\text { Hemorrhagic emergencies } \\
\text { Dystocia } \\
\text { Acute fetal distress } \\
\text { Prophylactic cesarean section } \\
\text { Other diagnosesb } \\
\end{array}$ & $\begin{array}{l}188(8) \\
105(7) \\
110(8) \\
62(7) \\
49(7) \\
33(8)\end{array}$ & $\begin{array}{c}1.20(0.87-1.36) \\
1.01(0.85-1.19) \\
1.11(0.83-1.38) \\
1.02(0.86-1.21) \\
1 \\
1.17(0.79-1.28)\end{array}$ & $\begin{array}{l}- \\
- \\
- \\
- \\
-\end{array}$ & $\begin{array}{l}0.677 \\
0.929 \\
0.582 \\
0.908 \\
\\
0.544\end{array}$ \\
\hline $\begin{array}{l}\text { Comorbidities } \\
\text { No } \\
\text { Yes }\end{array}$ & $\begin{array}{c}436(7) \\
134(11)\end{array}$ & $1.62(1.32-1.99)$ & $1.54(1.25-1.90)$ & $<0.001$ \\
\hline Mean duration of hospital stay (days) (SD) & $4(1)$ & $0.97(0.90-1.04)$ & - & 0.345 \\
\hline $\begin{array}{l}\text { Maternal outcome } \\
\text { Discharge } \\
\text { Transfer } \\
\text { Death }\end{array}$ & $\begin{array}{l}564(8) \\
1(5) \\
5(11)\end{array}$ & $\begin{array}{c}1 \\
0.67(0.09-5.00) \\
1.50(0.59-3.81)\end{array}$ & - & $\begin{array}{l}0.693 \\
0.395\end{array}$ \\
\hline
\end{tabular}

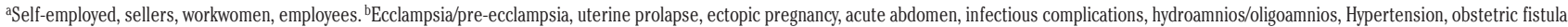




\section{References}

1. CDC. Healthcare-associated infections [Internet]. 2012 [cited 2016 Jun 14]. Available from: https:/www.cdc.gov/ $\mathrm{HAI} / \mathrm{ssi} / \mathrm{ssi}$.html

2. Conroy K, Koenig AF, Yu YH, et al. Infectious morbidity after cesarean delivery: 10 strategies to reduce risk. Rev Obstet Gynecol 2012;5:69-77.

3. Chu K, Maine R, Trelles M. Cesarean section surgical site infections in subSaharan Africa: A multi-country study from Medecins sans Frontieres. World J Surg. 2015;39:350-5.

4. Saizonou JLO. Epidémiologie et prise en charge des infections du per-partum à la maternité du centre hospitalier départemental de l'Ouémé -Plateau au Bénin. 2014;8688:1-9.

5. Ngowa JDK, Ngassam A, Fouogue JT, et al. Complications maternelles precoces de la cesarienne: a propos de 460 cas dans deux hopitaux universitaires de Yaounde, Cameroun. Pan Afr Med J 2015;21:265

6. Jido T, Garba I. Surgical-site infection following cesarean section in Kano, Nigeria. Ann Med Health Sci Res 2012;2:33.

7. WHO. Prevention of nosocomial infections. Practical guide. 2nd Ed. Geneva: WHO; 2002.

8. Delamou A, Dubourg D, Beavogui AH, et al. How has the free obstetric care policy impacted unmet obstetric need in a rural health district in guinea? PLoS One 2015;10.

9. MSHP/OMS. Rapport de la Situation Epidémiologique Maladie a Virus Ebola en Guinée. Rapport du 28 Avril 2016. 2016.

10. Toure A, Traore FA, Sako FB, et al. Knowledge, attitudes, and practices of health care workers on Ebola virus disease in Conakry, Guinea: A crosssectional study. J Public Heal Epidemiol 2016;8:12-6.

11. Delamou A, Beavogui AH, Kondé MK, et al. Ebola: Better protection needed for Guinean health-care workers. Lancet. Elsevier Ltd; 2015;385:503-4.

12. Baize S, Pannetier D, Oestereich L, et al. Emergence of Zaire Ebola Virus Disease in Guinea. N Engl J Med 2014;371:1418-25.

13. Cooper C, Fisher D, Gupta N, et al. Infection prevention and control of the Ebola outbreak in Liberia, 2014-2015: key challenges and successes. BMC Med. BMC Medicine 2016;14:2.

14. Shrivastava SR, Shrivastava PS, Ramasamy J. Exploring the importance of infection prevention and control measures in the 2014 outbreak of ebola. Int J Prev Med 2015;2015:2014-5.

15. Presidence de la Republique. Troisieme Recensement General de la Population et de l'Habitat (RGPH), 2014, Republique de Guinee. 2015.

16. Institute of Statistics; Ministry of Planning. Guinea Demographic and Health and Multiple Indicators Survey 2012. 2013.

17. Shrivastava S, Shrivastava P, Ramasamy J. Ebola disease: Infection prevention and control in hospital and community settings. Iran J Nurs Midwifery Res 2015;20:526.

18. WHO. Essential health services situati- on reports: Background 2017. Available from: http://www.who.int/csr/disease/ ebola/health-systems-recovery/ehsbackground/en/

19. Diakite AS. L'épidémie à virus Ébola en Guinée, ses conséquences sanitaires et socio-économiques. Bull Acad Natl Med 2014;198:1505-14.

20. Delamou A, Hammonds RM, Caluwaerts $\mathrm{S}$, et al. Ebola in Africa: Beyond epidemics, reproductive health in crisis. Lancet 2014;384:2105.

21. Camara BS, Delamou A, Diro E, et al. Effect of the 2014/2015 Ebola outbreak on reproductive health services in a rural district of Guinea: An ecological study. Trans R Soc Trop Med Hyg 2017;111.

22. Garner BH, Anderson DJ. Surgical Site Infections: An Update. Am J Infect Control 2016:S0196:30961-0.

23. Pop-Vicas A, Musuuza JS, Schmitz M, et al. Incidence and risk factors for surgical site infection post-hysterectomy in a tertiary care center. Am J Infect Control 2017;45:284-7.

24. WHO. Global guidelines for the prevention of surgical site infection. 2016. $186 \mathrm{p}$.

25. Allegranzi B, Zayed B, Bischoff $\mathrm{P}$, et al. New WHO recommendations on intraoperative and postoperative measures for surgical site infection prevention: an evidence-based global perspective. Lancet Infect Dis 2016;16:e288-303.

26. Delamou A, Delvaux T, El Ayadi AM, et al. Public health impact of the 20142015 Ebola outbreak in West Africa: seizing opportunities for the future. BMJ Glob Heal 2017;2:e00202. 